\title{
O CORPO NOSSO DE CADA DIA: CORPOREIDADE E FORMAÇÃO DE PROFESSORES
}

\author{
Adriane Ogeda Guedes ${ }^{1}$
}

INTRODUÇÃO:

\begin{abstract}
(...) - Vede este corpo, que salta como a chama sucede à chama, vede como pisa e esmaga o que é verdadeiro! Como destrói furiosamente, alegremente, o próprio lugar onde está, e como se embriaga do excesso das mudanças!(...)

E o corpo, que é o que é, eis que não pode mais se conter na extensão! - Onde ficar? - Onde mudar?(...) sendo coisa explode em acontecimentos! Exalta-se! - E como o pensamento excitado toca toda sua substância, vibra entre os tempos e os instantes, atravessa todas as diferenças; e como em nosso espírito se formam simetricamente as hipóteses, e como os possíveis se ordenam e se enumeram - esse corpo exercita-se em todas as suas partes, e se combina consigo mesmo, e dá forma depois de forma, e sai sem cessar de si.

(Paul Valéry, 1986)
\end{abstract}

\begin{abstract}
O corpo traz uma história, uma espécie de memória, nos tendões, nos órgãos, no padrão da respiração. Memória afetiva dos tempos de infância, memória muscular do desenvolvimento motor nos primeiros anos de vida, e também memória de cada tombo, cada salto, cada cambalhota, cada dança. (Vianna e Castilho, 2002, p. 25)
\end{abstract}

"Ninguém sabe o que pode um corpo", afirma Espinosa. Para o autor, a potência é o que define nossos corpos. Potência que se amplia ou restringe a partir das relações que vivenciamos. Seres da afecção, tudo nos afeta e transforma - ambientes, relacionamentos, cores, sons, sabores. O que experimentamos permite expandir ou limitar nossa possibilidade de ser novamente afetados. Vai compondo o que conhecemos de nós mesmos e o que compreendemos do mundo em que vivemos. O autor associa também a liberdade com essa capacidade de permeabilidade e sintonia entre o que se passa em nós e fora de nós, corpos afetados por objetos exteriores. Seríamos livres quando, “fortes de corpo e alma, somos capazes da multiplicidade simultânea, isto é, de um corpo capaz de ser afetado e afetar outros corpos de inúmeras maneiras simultâneas e de uma alma capaz de pensar inúmeras

\footnotetext{
${ }^{1}$ Psicóloga e Pedagoga com Mestrado e Doutorado em Educação pesquisando formação de professores. Formada em Técnica em bailarina pela Escola Angel Vianna, Especialista em Educação Infantil (PUC RJ), Alfabetização (UFRJ) e Docência do Ensino Superior (UNIRIO). Professora Adjunta da Unirio, na área de Alfabetização do Departamento de Didática. adrianne.ogeda@gmail.com
} 
idéias e sentir inúmeros afetos simultâneos". (Espinosa, 1997: p. 240). Inicio com a instigação de Espinosa, filósofo holandês do século XVII, apenas para provocar as questões inicias desse artigo.

Como temos nos afetado pelas experiências que vivemos na contemporaneidade? Como elas têm potencializado (ou despontencializado) nossos corpos? Nos tornado capazes e potentes para novos afetos? Como têm forjado o que conhecemos e a forma como conhecemos? E de que modo, tomando a formação docente como campo de exploração, como os espaços formativos integram a dimensão do corpo em suas práticas e fundamentos? Esse artigo produzido no contexto da pesquisa "Corpo, arte e natureza: investigando metodologias de formação de professores"”, volta seu foco especialmente para a formação inicial do professor realizada no Curso de Pedagogia, tomando a disciplina obrigatória Corpo e Movimento como lócus da investigação. Além das questões relativas à formação inicial, inquieta-nos considerar o contexto em que atuarão os professores. Professores brasileiros, que habitam um grande centro urbano como é a nossa cidade do Rio de Janeiro. Sujeitos em formação, muitos realizando a formação em nível superior mas já em exercício nas séries iniciais. Professores às portas de ingressar em uma carreira desafiante, marcada por disputas constantes por melhores condições de trabalho e por uma perspectiva de trabalho que anuncia dificuldades, limites e possibilidades.

E que contexto é esse? Não são poucos os depoimentos de nossos estudantes, especialmente os que já atuam em escolas, que nos revelam um cotidiano que caminha "contra o corpo" e suas demandas. Desafios que envolvem espaços, tempos e um corpo, espremidos e assolados pelas lógicas contemporâneas.

Salas cheias, espaços nem sempre adequados para o trabalho. Tempo demarcado por uma rotina fracionada, que impõe ritmos, nem sempre aqueles que combinam com o corpo e suas necessidades. Pouco (e por vezes nenhum) contato com elementos da natureza: terra, sol, água e ar puro. Realidade do cotidiano de muitos de nós, que atuamos nos diversos segmentos educacionais, da Educação Infantil ao Ensino Superior.

O tempo acelerado, conduzindo um cotidiano apressado e turbulento. No caso do Rio de Janeiro, trânsito difícil, transportes públicos deficitários, longas distâncias. Premidos por um "tempo sem tempo", fazemos as refeições correndo, nos relacionamos com pressa. Não há tempo para a escuta tranqüila, tão pouco para a contemplação. Há sempre um trabalho a nossa espera a ser feito. Atrasados, aos sobressaltos. Tarefas que se acumulam numa lógica produtivista que nos assola.

\footnotetext{
${ }^{2}$ Pesquisa cadastrada no Departamento de Pesquisa da Universidade Federal do Estado do Rio de Janeiro desde 2014.
} 
Corpo restrito a espaços que limitam e definem uma posição a ser adotada na maior parte do tempo (sentados), que restringem os movimentos amplos, que nos distanciam do contato com a natureza. Premido por um tempo acelerado, que nos faz "correr contra o tempo", para dar conta dos prazos que se acumulam, para caber nas rotinas estabelecidas e inflexíveis. Somando-se a isso, a essa cultura do corpo disciplinado, o corpo como objeto de consumo. Cercados por uma hipervalorização do corpo jovem, magro e esguio, por um padrão de beleza massificado que favorece a que não nos percebamos como corpos belos quando fora desse padrão. Nas bancas, revistas anunciam dietas mirabolantes e suas promessas, plásticas para “embelezar” os corpos. Nas capas estão estampadas os ícones da beleza, devidamente fotoshopadas, criando a imagem de uma suposta perfeição inatingível.

Nesse contexto de formação e de vida do professor, de que modo o conhecimento e a experiência de conhecer se dão nesse espaço, nesse tempo, com esse corpo. Hoje. Conhecer é tarefa complexa que envolve o sujeito de forma integral. Afeto, cognição, sentidos.

Esse artigo, assentando-se nas pesquisas narrativas e biográficas (GUEDES E CHAVES, 2016), toma como provocação essas questões iniciais que impactam a vida de todos nós, focalizando o professor em formação e refletindo a respeito da necessidade de levar em conta nos cursos de formação inicial do professor, nas práticas e currículos, espaços e tempos que propiciem experiências de conhecer com o corpo inteiro, de auto cuidado e conhecimento de si, dimensões que consideramos fundamentais para o exercício da docência. Tomamos como foco pensar uma formação que integre as dimensões do corpo e do movimento no processo de conhecer como fundamentais para construção de uma experiência formativa potente, que abra um espaço sensível, de canais de prazer com a vida e que sustente a experiência e a existência.

Inicio recorrendo a um exercício biográfico (DOMINICÉ, 1990), resgatando o sentido que o trabalho de corpo foi assumindo em meu percurso formativo e as experiências que forjaram a forma de compreendê-lo e que hoje compõem a maneira como penso a formação de professores. Trago também alguns depoimentos de estudantes da disciplina que ministro, "Corpo e Movimento" do Curso de Pedagogia da Universidade Federal do Estado do Rio de Janeiro, que evidenciam a autoimagem que possuem de si mesmos no início da disciplina e no meio da mesma, propiciando refletir sobre a maneira como se vêem e como as experiências de autoconhecimento os impactou. Em suma, a proposta é pensar de que forma os espaços e tempos dos cursos de Pedagogia, no que se refere então a formação inicial do professor, têm incluído em suas atividades de formação experiências que aproximem os sujeitos de seu corpo. Como esse corpo vive na graduação? De que forma experimenta as possibilidades de fruição, de brincadeira, de autoconhecimento? Esse artigo visa por em cena a 
necessária reflexão sobre uma formação de professores que considere o corpo em sua dimensão sensível.

\section{PRIMEIROS PASSOS: EU, MEU CORPO DE PROFESSORA SE FAZENDO NA HISTÓRIA DOS ENCONTROS}

Minha trajetória de formação, seja nos espaços formativos, seja nas experiências profissionais que também nos formam, sempre esteve ligada de alguma forma às artes de uma forma mais ampla e às práticas corporais em especial. A primeira experiência mais marcante de trabalho corporal se deu no início dos anos 1980 com a "Ginástica Orgânica”, ministrada pelo falecido professor e bailarino Carlos Afonso. Bailarino do antigo Grupo Coringa, grupo criado na década de 1970 pela uruguaia Graciela Fuigueroa (Ruiz, 2013) em pleno contexto de Contra-Cultura. O Coringa pensava outra forma de fazer arte, representaram os primeiros passos da dança contemporânea no Brasil provocando grande impacto na cena carioca. De lá saíram muitos artistas, educadores e terapeutas corporais.

Ainda que à época, quando não tinha mais de 20 anos de idade, os sentidos daquela experiência não fosse claros, a forma como aquele trabalho me mobilizou dava pistas de um caminho corporal que me interessava e que ia na contramão da maior parte das atividades que conhecia até então (havia feito vários tipos de dança e práticas esportivas). A dinâmica das aulas se caracterizava por seu fluxo ininterrupto de movimentos realizados em um grande círculo. Música, respiração, sons e entrega. Fruição. Uma experiência quase ritualística vivida em grupo. Pela primeira vez experimentava uma proposta corporal que não era focada em um conjunto de técnicas de movimentos que deveriam ser repetidos seguindo um ritmo qualquer ou de exercícios mecânicos com objetivo de fortalecer, alongar ou qualquer outra dessas qualidades necessárias a um corpo que dança ou que quer trabalhar seu condicionamento. Muito embora também fortalecessem, alongassem, disponibilizassem para a dança. A minha dança.

Isso encantou-me. A possibilidade de construir uma dança própria, autoral, nascida da experiência com o livre movimento, a música e as provocações vividas em grupo. Outras práticas foram afirmando para mim esse lugar, naquela época bastante intuitivo, de um trabalho corporal que primava pela sensibilidade, pela escuta do próprio corpo, pelo movimento consciente e significativo. Sentia-me dona do movimento, inteira no gesto e no ritmo. Eu era o meu corpo. Era a minha dança. Outras práticas, tais como a yoga, a capoeira, a dança criativa com Neide Neves, então esposa de outro nome importante no campo da dança, Rainer Vianna, fizeram parte do conjunto de experiências corporais que foram afirmando para mim um sentido especial em mover o corpo: habitá-lo! Integrando gesto, força, impulso, experimentação de forma não mecanizada. Com sentido, com sabor. 
Provocada por essas experiências em meados dos anos 1980 integrei o Centro de Estudos do Movimento de Angel Vianna para fazer o curso técnico de formação em bailarina. Essa experiência marcou fortemente minha compreensão a respeito do meu próprio corpo e da necessidade vital de considerar a dimensão corporal na vida de um modo geral. Paralelamente trabalhava em escolas com Educação Infantil, cursava a graduação em Psicologia, freqüentava cursos de literatura infantil, arte, bonecos e nos finais de semana trabalhava com teatro de fantoches e em animação de festas infantis. Um caldo de experiências que não se conectava com clareza na época mas que foram sendo costuradas nos anos que se seguiram quando trabalhei como professora de artes em diversas escolas, fundei e coordenei uma Instituição de Educação Infantil, trabalhei com formação de professores e segui a vida acadêmica nos estudos de mestrado, doutorado, ingressando em 2011 no quadro de professores da Universidade Federal do Estado do Rio de Janeiro.

Retomar brevemente esse percurso de experiências, rico e diverso, tem aqui uma função em especial. Localizar na trajetória biográfica, na minha própria formação estética, como foi se constituindo historicamente o sentido que a arte e o corpo têm hoje na minha prática como formadora de professores. Para mim as experimentações que vivi no curso de formação da Angel Vianna foram definidoras de um modo de lidar com o meu próprio corpo e movimento. Lá travei contato com modalidades de trabalho distintas e seus elementos, ballet clássico, contemporâneo e moderno, elementos do teatro, música e diversas linhas de trabalho tais como as de Rudolf Laban, a Técnica de Alexander, Eutonia de Guerda Alexander e a própria proposta dos Vianna de Consciência corporal. Espaço, tempo, qualidades de movimento, impulso, queda, ritmo, respiração, consciência, ossos, articulações, pele, quedas, saltos, giros. Meu corpo experimentava tudo isso vivamente, cansado muitas vezes de um dia inteiro com crianças e em estudo (atuava então em Escolas de Educação Infantil). Não queria ser bailarina, me faltava a dedicação integral necessária para tanto, mas aqueles elementos me pareciam cruciais, intuía.

E de fato o foram. E de fato o são. Com crianças e adultos, de alguma forma, sempre estive atenta a essa dimensão do corpo e do movimento e tais dimensões me levaram a ter interesse por campos do conhecimento que convidam a pensar o sensível, a criação, a arte, a forma como construímos conhecimento. Experiências que apontavam para a necessidade de que a educação compreendesse o sensível, de que esse campo é vital para a formação humana. Os caminhos e experiências foram muitos e muitos desvios poderiam ser feitos aqui. Mas sigamos o caminho que traço entre esses primeiros passos e os passos que hoje dou na direção de formar professores na Escola de Educação da Universidade Federal do Estado do Rio de Janeiro. 
Nesse sentido, chego a graduação da Unirio assumindo a disciplina Corpo e Movimento. Momento de trazer à baila a formação que fui tecendo ao longo da minha trajetória. E como encontro esses corpos? O que me dizem? O que dizem?

\section{PASSOS DE DANÇAR JUNTO: UMA EXPERIÊNCIA DE EDUCAÇÃO CORPORAL.}

É um grave equívoco imaginar que idéias bem articuladas inteligentemente são suficientes para dar conta da "explicação" da produção de realidade. O excesso de comunicação e de interpretações

sobre a origem e a finalidade disso ou daquilo encobrem os gritos de um corpo violentado. Quando afirmamos que ninguém está destinado à tristeza é porque ela, ao contrário do senso comum, não possui uma origem psicológica - nos parece que a tristeza manifesta um grito do corpo, ou seja, uma indicação de que algo sobre o corpo age de modo contrário à sua tendência essencial. Violentado, o corpo grita e grita, não cessa de gritar. Mas esses gritos não costumam ser ouvidos com atenção. (Amauri Ferreira, Aforismos Vol. II, 2014, p. 26))

A única finalidade da vida é mais vida. Se me perguntarem o que é essa vida, eu lhes direi que é mais liberdade e mais felicidade. São vagos os termos. Mas, nem por isso eles deixam de ter sentido para cada um de nós. À medida que formos mais livres, que [...] ganharmos critérios mais finos de compreensão, nessa medida nos sentiremos maiores e mais felizes. A finalidade da educação se confunde com a finalidade da vida. (Anísio Teixeira, 1934)

Como conhecemos? De que forma construímos os conhecimentos, nós, adultos em formação? Como se articulam experiências sensíveis com a compreensão intelectiva das mesmas? Essas têm sido questões que mobilizam o campo da formação de professores, desafiando a pensar caminhos teórico metodológicos que garantam uma maior articulação entre teoria e prática. Pimenta (2005), lembra da afirmação popular, tão comumente repetida por muitos dos nossos estudantes, Na prática a teoria é outra. No cerne desse ditado, sublinha a autora, constata-se que o curso de formação de professores nem fundamenta teoricamente a atuação da futura professora, nem torna a prática como referência para fundamentação teórica. Ainda que compreendamos a indissociabilidade entre essas duas dimensões - nossas ações, ainda que de forma pouco consciente, têm sempre um manancial de 
conceitos que as orientam - é um desafio sempre presente garantir que se articulem efetivamente na formação docente.

Portanto, o desafio de formar implica em considerar o compromisso praxiológico do professor, ou seja, levar em conta de que forma as ações docentes são direcionadas, o que as sustenta, o que as constitui.

Instigada por essas questões, tenho experimentado em minha atuação como professora formadora alguns caminhos. Trago aqui algumas reflexões sobre o processo, ainda em andamento, vivido em especial em Corpo e Movimento, disciplina obrigatória do currículo do Curso de Pedagogia da Universidade Federal do Estado do Rio de Janeiro (UNIRIO). O foco dessa disciplina é um convite para promover com maior liberdade experiências que fujam do modelo mais usual de aula na universidade - leitura e discussão de textos, exposição oral, etc. Assim, pensei a disciplina buscando outras formas em que fosse possível organizar as aulas de modo que os estudantes fossem convidados a experimentar, vivenciar. Ao dar destaque a experiência experimentada na disciplina Corpo e Movimento, busco evidenciar os processos de autoconhecimento mobilizados a partir das experiências corporais vividas com o grupo, em que as questões referentes ao corpo articularam-se com uma prática de autoconhecimento, tornando a compreensão das necessidades desse corpo mais evidentes e sentidas. Trago aqui apontamentos referentes a turma que acompanhei em 2014, a segunda em que assumi a disciplina.

A turma era constituída por aproximadamente 40 pessoas. Acontecia em uma sala convencional, como as salas das universidades o são. Cadeiras (muitas), quadro branco, chão de cimento frio. A nosso favor, janelas que se abrem ao costado da Urca, numa profusão de verde e céu. Muitas questões me foram endereçadas logo que o curso começou. Curioso que a forma como as aulas transcorriam e a própria proposta parecem ter funcionado como um convite aos desvelamentos, aos pedidos de ajuda. Foi assim que escutei muitos depoimentos sobre as condições de saúde em que se encontravam alguns dos estudantes, bem como as próprias dificuldades mais amplas que viviam em suas vidas pessoais fora da universidade. Recentes cirurgias, problemas de hérnia de disco, sobrepeso, sedentarismo, doenças mais graves como Parkinson e câncer, tensões no trabalho, dificuldades familiares. Ali desvelavam-se as mazelas, os mal estares de todos que, ao se confrontarem com a possibilidade de olhar para si, vinham à tona. Um convite? Pedido de ajuda? Um momento de "respiro"? Um "grito do corpo"?

Recebia esses "pedidos de ajuda" com o cuidado possível. Como parte do conjunto de atitudes que assumimos - eu e os três bolsistas de iniciação científica que trabalhavam comigo à época - na 
condução das aulas. É Leonardo Boff quem nos afirma ser o humano um "ser de cuidado", entendendo-o como mais do que um momento de atenção, mas com uma atitude de ocupação, preocupação, de responsabilização e de envolvimento afetivo com o outro (Boff, 1999, p. 99). Ouvir, perceber as necessidades particulares, acolher aos que se atrasavam, situando-os a respeito do que estava acontecendo, manter contatos ao longo da semana disponibilizando fontes de consulta para aprofundamento do que estávamos experimentando e estudando, bem como divulgar eventos ligados à disciplina fez parte das ações pedagógicas que assumimos. A atenção ao espaço físico e as condições de trabalho também foram importantes. A toda aula afastávamos os móveis, levávamos algum alimento (e convidávamos todos a fazerem o mesmo), disponibilizávamos colchonetes.

É Nunes (2003) quem nos aponta para esse hibridismo possível entre educação, saúde e arte, sem que as especificidades se apaguem e se obscureça o foco que ali vivíamos: estávamos em atividade de formação cujo foco era pensar diversos aspectos referentes à corporeidade na articulação com a educação e a saúde. Mas essas fronteiras são tão fixas assim? Até onde saúde e educação conversam estreitamente? Como a doença invade as salas de aula e interfere ou impacta as relações que empreendemos em nosso cotidiano? De que maneira um corpo em sofrimento, sem energia para mover-se e relacionar-se, com dores e limites imobilizadores e limitantes, pode de fato estar disponível para o encontro que é o fazer educativo? E se tais fronteiras são tênues, o que cabe a esse espaço formativo?

As aulas tiveram como foco propiciar a cada encontro experiências de consciência corporal, tomando como base, dentre outras referências, a metodologia de Consciência corporal da bailarina Angel Vianna, mais voltada para a idéia de processo do que propriamente de uma técnica. Nesse trabalho a conscientização do movimento é um aprendizado que se submete ao autoconhecimento proporcionado pelas práticas. Parte-se do corpo na direção de construir um sentido de pertencimento ao próprio corpo, integrando consciência e escuta simultaneamente (Teixeira, 2003, p. 72). Para tanto, além das práticas corporais é fundamental que se propicie um espaço coletivo para expressão e elaboração do que foi observado, sentido.

Logo no início do curso, em meados de agosto de 2014, propusemos que, após um momento de observação e percepção do próprio corpo, todos desenhassem a si próprios. Pedimos também que escrevessem suas impressões a respeito de si mesmos, a partir de algumas perguntas instigadoras: 1) Qual a relação com o meu corpo hoje?, 2) Como tenho habitado meu corpo?, 3) O que desejo para meu corpo daqui para frente? Alguns relatos falavam de uma relação como o próprio corpo marcada por tensões, dificuldades de aceitação, de lidar com as limitações e com as mudanças. Trago trechos desses relatos, utilizando pseudônimos para nomear os sujeitos, evitando assim expô-los. 
Hoje eu percebo que nunca tive uma boa relação com o meu corpo. Nunca o aceitei verdadeiramente. Tem sido difícil conviver com ele, as limitações só aumentam. Sei que a culpa é minha, pois sou eu quem o sobrecarrego. Envelhecer não tem sido fácil. (Maria)

Minha relação com meu corpo não vai muito bem pois não creio que esteja cuidando bem dele. Sinto ele tenso demais, com dores, musculatura pedindo socorro. Gostaria de sentir leveza e não tanta tensão. Desejo emagrecer, fazer algum exercício em benefício próprio, mas com prazer, chega de obrigação e que ele se sinta melhor, viva melhor. (Helena)

Sinto meu corpo tenso, limitado, controlado, um pouco desgastado da correria do dia a dia, sem tempo para mim ou cuidar de mim ou senti-lo. Gostaria de ter mais tempo para me dedicar a mim a o meu corpo, ou que a velocidade das coisas seja mais lenta, menos corrida para poder relaxar e me dar descanso. (Júlia)

Meu corpo hoje está repleto de inquietações e tensões ocorridas pelas situações do dia a dia. Na verdade meu corpo é sempre assim, é uma sensação de aprisionamento e ao mesmo tempo de agitação. Sensações estas que não mudam nunca. E o que desejo para o meu corpo é que ele se sinta livre, calmo e sem tensões. Se pudesse gostaria que ele voasse como um passarinho voando no lindo céu azul. Quero que meu corpo seja livre dessas sensações que me inquietam, é isso que tentarei fazer a partir de agora! (Aurora)

Essas primeiras impressões nos forneceram um panorama de como chegavam à disciplina aqueles corpos. Nossa observação também ia nos indicando os cuidados necessários: de quem nos aproximar para oferecer ajuda, a quem procurar no final da aula para saber mais particularmente como se sentia, como orientar ao longo das aulas àqueles que mostravam-se desconfortáveis com algumas posições ou mesmo com a própria dinâmica das aulas. Conversávamos após os encontros, os bolsistas e eu, e íamos trocando nossas impressões, identificando as necessidades que o trabalho apontava. Para alguns sentar no chão era tarefa exigente. Parte posterior do corpo mais encurtada, dificuldade na sustentação do tronco em posição ereta, sobrepeso. Para outros, o deslocamento e a exposição que se sentiam vivendo nas propostas de exploração do espaço e do movimento revelavam-se em um gestual mais tímido, retraído. Acolhíamos não apenas com nosso olhar, mas muitas vezes nos aproximando de cada um e oferecendo alternativas (“é possível fazer a atividade apoiando-se na parede, utilizando as mãos como sustentação").

A percepção do próprio corpo é fundamental para que não se embotem os sentidos, para que se "esteja presente no próprio corpo" (Vianna e Castilho, 2002, p. 23). Estar consciente de sua postura corporal, seu padrão de movimentação, as tensões localizadas na musculatura, os apoios e articulações permite que nos apropriemos de nossos recursos expressivos, de nosso corpo como um instrumento fundamental para a comunicação e relação com o outro. Nosso corpo comunica com seu gestual expressivo, dizendo de nós, de nossos afetos, disponibilidades, estados emocionais. Nosso 
corpo, "traz uma história, uma espécie de memória que está impregnada nos músculos, nos tendões, nos órgãos, no padrão de respiração.” (op.cit.). Encurtamentos na região posterior do corpo, dificuldades para sentar no chão em função, cansaço excessivo em atividades que envolvem movimentos mais vigorosos, dentre outros apontavam para a necessidade de vivenciarmos experiências que ampliem nosso conhecimento a respeito do nosso próprio corpo. Expandindo as possibilidades de movimento, de disponibilidade corporal para o jogo, a brincadeira, o contato, a troca. Reconduzindo-o para o bem estar e a criação.

Berge (1983) chama atenção para a reação do corpo à adaptação as situações nem sempre tão favoráveis do cotidiano contemporâneo, em que temos, mais das vezes, rotinas que nos impõe horas de imobilismo, sedentarismo, excesso de ruídos, tempo escasso dentro outros aspectos. Condições que nos deixariam com a sensibilidade receptiva mais protegida e represada. Audição, olfato, visão, tato e nosso sentido espaço temporal ficam afetados. “(...) A mesma ameaça nos espreita no campo gestual. Não temos mais consciência de nosso corpo. De tanto sermos condenados à imobilidade num espaço restrito, os membros, os músculos perdem o gosto pelo movimento, tornam-se desajeitados (...)." (Berge, 1983, p. 24). Para a autora, que se dedica a pensar em especial o trabalho corporal com crianças, a receptividade sensorial precisaria ser reeducada e para isso, um dos caminhos possíveis consistiria na promoção de experiências de consciência corporal que levem os sujeitos a perceberem com maior sutileza, ampliando sua capacidade sinestésica - de que nos informa sobre os sentimentos que temos sobre nós próprios, sobre a maneira como nos movemos, como nos percebemos, etc.

Foi possível perceber que as experiências promovidas na disciplina de Corpo e Movimento promoviam uma espécie de refinamento, de abertura para a receptividade sensorial, aprimorando conhecimentos do campo perceptivo. O contato com a auto-percepção e a percepção do outro, em proposta que envolviam a pesquisa do movimento, do espaço, dos ritmos e das possibilidades de perceber aspectos sensíveis da sua própria corporeidade pareciam mobilizar nos participantes uma escuta ampliada para si próprio e, muitos relatavam, também para o outro.

Finalizo esse artigo realçando o papel da formação do professor, como espaço de integração das dimensões afetivas, cognitivas e sensíveis do humano. Nossa pesquisa tem trilhado investigações a respeito dos caminhos formativos que podem contribuir para essa integração. Alguns elementos das experiências na disciplina Corpo e Movimento têm indicado pistas que indicam férteis caminhos para a continuidade da pesquisa em tela. 


\section{REFERÊNCIAS BIBLIOGRAFICAS}

ESPINOSA, Baruch de. Ética: demonstrada à maneira dos geômetras. Os Pensadores. Trad. Joaquim de Carvalho, Joaquim Ferreira Gomes e Antônio Simões. São Paulo: Nova Cultural, 1997.

Dominicé, Pierre. L'histoire de vie comme processus de formation. Paris: Édition L'Harmattan, 1990.

BERGE, Yvonne. Viver seu corpo, por uma pedagogia do movimento. SP: Martins Fontes, 1983.

BOFF, Leonardo. Boff L. Saber cuidar: ética do humano compaixão pela terra. Petrópolis (RJ): Vozes; 1999.

FERREIRA, Amauri. Aforismos, Vol. II. Em: < www.amauriferreira.com>. Acesso em: 20 de setembro de 2014.

GUEDES, Adrianne e MONTALVERNE, Iduina. Textos memorialísticos na formação docente: narrativa de professores. Revista Linha Mestra Ano X. No. 30 (set.dez.2016) ISSN: 1980-9026.

NUNES, Everardo Duarte. As ciências humanas e a saúde: algumas considerações. Revista Brasileira de Educação Médica, Rio de Janeiro, v. 27, n. 1, p. 65-71, 2003.

PIMENTA, Selma Garrido, LIMA, Maria Socorro Lucena. Estágio e docência: diferentes concepções. Revista Poíesis Volume 3, Números 3 e 4, pp.5-24, 2005/2006

RUIZ, Giselle. Graciela e Grupo Coringa: A dança contemporânea carioca dos anos 1970/80”. RJ: Mauad X, 2013.

Spinoza, Benedictus de, 1632-1677.Ética / Spinoza ; [tradução e notas de Tomaz

Tadeu]. Belo Horizonte : Autêntica Editora , 2007.

TEIXEIRA, Letícia. Conscientização do movimento em CALAZANS, J., CASTILHO, J. e GOMES, S. (coords.). Dança e educação em movimento. São Paulo: Cortez, 2008.

VALERY, Paul. A alma e a dança. RJ: Imago, 1996.

VIANNA, Angel e CASTILHO, Jacyan. Percebendo o corpo. RJ: DP\&A, 2002. 


\section{O CORPO NOSSO DE CADA DIA: CORPOREIDADE E FORMAÇÃO DE PROFESSORES}

RESUMO:

Este artigo foi produzido no contexto da pesquisa "Corpo, arte e natureza: investigando metodologias de formação docente" (UNIRIO). Seu objetivo é apresentar alguns questionamentos inicias a cerca da necessária integração de estudos e experiências voltados para a dimensão corporal nos processos formativos do professor, centrando-se na formação inicial. Para tanto, inicia evidenciando os desafios do contexto educacional e os limites de espaço e tempo presentes nas instituições educacionais. Em seguida, assentando-se nas pesquisas narrativas e biográficas, traz elementos da trajetória de formação estética da autora com vistas e destacar elementos que podem contribuir para as práticas formativas para, em seguida, apresentar e refletir sobre alguns dos aspectos da experiência vivenciada pela autora ao ministrar a disciplina obrigatória Corpo e Movimento do Curso de Pedagogia da Universidade Federal do Estado do Rio de Janeiro. Como conclusão provisória, por tratar-se de uma pesquisa em andamento, sublinha-se o papel da formação como espaço de promoção de mudanças de uma sociedade heterogênea, que busca qualidade de vida para todos e que considere às expressões corporais dos sujeitos e suas necessidades de integrá-las em seu processo de aprendizado.

PALAVRAS-CHAVE: Corpo. Educação. Formação docente.

\section{THE BODY OUR EVERY DAY: CORPORATION AND TEACHER TRAINING}

ABSTRACT:

This article was produced in the context of the research "Body, art and nature: investigating methodologies of teacher education" (UNIRIO). Its objective is to present some initial questions about the necessary integration of studies and experiences directed to the corporal dimension in the formative processes of the teacher, focusing on the initial formation. To do so, it begins by highlighting the challenges of the educational context and the limits of space and time present in educational institutions. Then, based on narrative and biographical research, it brings elements of the trajectory of aesthetic formation of the author with views and highlight elements that can contribute to the formative practices to then present and reflect on some of the aspects of the experience experienced by the author To teach the compulsory discipline Body and Movement of the Pedagogy Course of the Federal University of the State of Rio de Janeiro. As an interim conclusion, since it is an ongoing research, the role of training as a space for the promotion of change in a heterogeneous society, which seeks quality of life for all and that considers the body expressions of the subjects and their needs of integrating them into their learning process.

Key-words: Body. Education. Teacher training.

\section{EL CUERPO NUESTRO DE CADA DÍA: CORPOREIDAD Y FORMACIÓN DE PROFESORES}

RESUMEN:

Este artículo fue producido en el contexto de la investigación "Cuerpo, arte y naturaleza: investigando metodologías de formación docente" (UNIRIO). Su objetivo es presentar algunos cuestionamientos iniciales a cerca de la necesaria integración de estudios y experiencias volcados a la dimensión corporal en los procesos formativos del profesor, centrándose en la formación inicial. Para ello, inicia evidenciando los desafíos del contexto educativo y los límites de espacio y tiempo presentes en las instituciones educativas. A continuación, asentándose en las investigaciones narrativas y biográficas, trae elementos de la trayectoria de formación estética de la autora con vistas y destacar elementos que pueden contribuir a las prácticas formativas para, a continuación, presentar y reflexionar sobre algunos de los aspectos de la experiencia vivenciada por la autora al ministrar la disciplina obligatoria Cuerpo y Movimiento del Curso de Pedagogía de la Universidad Federal del Estado de Río de Janeiro. Como conclusión provisional, por tratarse de una investigación en marcha, se subraya el papel de la formación como espacio de promoción de cambios de una sociedad heterogénea, que busca calidad de vida para todos y que considere las expresiones corporales de los sujetos y sus necesidades de integrarlas en su proceso de aprendizaje.

PALABRAS CLAVE: Cuerpo. Educación. Formación docente. 